\title{
DİŞ BEYAZLATMA İŞLEMİNİN LİTYUM DİSİLİKAT SERAMİĞİN BAĞLANMA DAYANIMINA ETKİSi ${ }^{\neq}$
}

\section{THE EFFECT OF TOOTH BLEACHING ON THE SHEAR BOND STRENGTH OF A LITHIUM DISILICATE CERAMIC ${ }^{\neq}$}

Uzm.Dt. Merve YILDIRAK ${ }^{*}$

\author{
Doç.Dr. Rıfat GÖZNELI ${ }^{*}$
}

\author{
Makale Kodu/Article code: 3955 \\ Makale Gönderilme tarihi: 14.01 .2019 \\ Kabul Tarihi: 18.02 .2019 \\ DOI : $10.17567 /$ ataunidfd.528333
}

Merve Yıldırak: $O R C I D I D$ : 0000-0001-6974-1534

Rifat Gözneli: ORCID ID: 0000-0002-0582-9542

\section{öz}

Amaç: Bu çalışmanın amacı, LED ışık ile aktive edilen \%32'lik hidrojen peroksit diş beyazlatma ajanı uygulamasının, farklı periyotlarda lityum disilikat veneerlerin adeziv rezin simantasyonu sonrasındaki makaslama bağlanma dayanımlarına etkisini incelemektir.

Materyal ve Metod: Kırkbeş adet çekilmiş, üst santral insan dişi 3 gruba ayrılmıştır $(n=15)$. Kontrol grubu (K) olarak tasarlanan gruba beyazlatma işlemi uygulanmadan dişler mine seviyesinde prepare edilip, lityum disilikat veneerlerin simantasyonu yapılmıştır. Beyazlatma gruplarındaki örneklerin labial yüzeylerine LED ışık ile aktive edilerek \% 32 'lik hidrojen peroksit ajan uygulanmıştır. Beyazlatma işlemini takiben hemen (Grup B0), diş mine seviyesinde prepare edilip simantasyonları yapılmıştır. Diğer beyazlatma grubundaki örnekler (Grup B7), beyazlatma işlemini takiben 7 gün $37^{\circ} \mathrm{C}$ distile su içerisinde saklanıp, preparasyon ve simantasyonları yapılmıștır. Simantasyon sonrası her grup 24 saat $37^{\circ} \mathrm{C}$ distile su içerisinde bekletilip örneklerin makaslama bağlanma dayanımları üniversal test cihazında dakikada $0,5 \mathrm{~mm}$ ilerleme hızıyla ölçülmüştür. Diş ve seramik örneklerin kopma paternleri ışık mikroskobu altında incelenmiştir. Normal dağı̆ım gösteren verilerin karşılaştırılmasında tek yönlü varyans analizi (One-way ANOVA) kullanılırken, gruplar arasındaki farkıılığın nereden kaynaklandığını bulmak için Bonferroni düzeltmeli ortalama karşılaştırması yapılmıştır.

Bulgular: K grubunun ortalama makaslama bağlanma dayanımı değerleri 30,04 MPa iken, B0 grubunun ortalama makaslama bağlanma dayanımı değerleri 20,34 MPa'a düşmüş ve B7 grubunda ise 27,02 MPa'a çıkmıştır. Beyazlatmadan hemen sonra restore edilen dişlerde bağlanma kuvveti anlamlı miktarda azalmıştır $(p<0,001)$. K grubunda tip 1 ve tip 3 kopma paternleri görülürken, tip 2 kopma paterni görülmemiştir. B0 grubunda tip 2 ve tip 3 kopma paterni bulunurken, tip 1 kopma paterni görülmemiştir. B7 grubunda ise bütün kopma paternleri görülmüştür.

Sonuç: Beyazlatma işlemini takiben dişlere restorasyon uygulanması rezin simanın mineye bağlantısını olumsuz etkilemektedir. Tam seramik restorasyon yapılacak dişlere LED ile aktive edilen beyazlatma işlemi uygulanması planlanıyorsa beyazlatma işlemi sonrası en az 1 hafta beklenmesi önerilebilir.

Anahtar kelimeler: LED, hidrojen peroksit, rezin siman, makaslama bağlanma dayanımı.

\section{ABSTRACT}

Aim: The aim of this study was to investigate the effect of $32 \%$ hydrogen peroxide bleaching agent activated by LED on the shear bond strength of lithium disilicate veneers after adhesive resin cementation.

Materials and Methods: Forty-five extracted human maxillary central teeth were divided into 3 groups $(n=15)$. The control group $(\mathrm{K})$ was designed as without bleaching and the teeth were prepared at the enamel surfaces and lithium disilicate veneers were cemented with adhesive resin cement. The other groups, $32 \%$ hydrogen peroxide agent activated by LED was applied to the labial surfaces of teeth. Following the bleaching immediately, tooth reduction was made on enamel surfaces and cemented with adhesive resin cement (Group B0). The samples of the other bleaching group (Group B7) were stored in $37^{\circ} \mathrm{C}$ distilled water for 7 days after bleaching then, tooth reduction was made on enamel surfaces and cemented with adhesive resin cement. After cementation, each group was kept in $37^{\circ} \mathrm{C}$ distilled water for 24 hours and the shear bond strength values were measured by a universal testing machine with a crosshead speed of $0,5 \mathrm{~mm} / \mathrm{min}$. The failure modes of tooth and ceramic samples were examined under light microscope. One way ANOVA test was used in comparison of groups and Post hoc Bonferroni multiple comparison test was utilized to specify the differences.

Results: The mean shear bond strength values of the $\mathrm{K}$ group were $30.04 \mathrm{MPa}$, while in B0 group decreased to $20.34 \mathrm{MPa}$ and in B7 groups increased to $27.02 \mathrm{MPa}$. Immediately after bleaching, the shear bond strength values of the teeth was significantly reduced $(p<0.001)$. While type 1 and type 3 failure modes were observed in group $K$, type 2 was not observed. While type 2 and type 3 failure modes were found in group B0, type 1 failure mode was not observed. All failure modes were observed in group B7.

Conclusion: Adhesive restoration of the teeth after bleaching negatively affects the bonding of resin to the enamel. It is recommended to wait for at least 1 week after bleaching activated by LED, if it is planned to make an all-ceramic restoration. Keywords: LED, hydrogen peroxide, resin cement, shear bond strength.

\footnotetext{
* Marmara Üniversitesi Diş Hekimliği Fakültesi, Protetik Diş Tedavisi Anabilim Dalı İstanbul, Türkiye,

${ }^{\ddagger}$ Bu çalışma, Marmara Üniversitesi Bilimsel Araştırma Projeleri Komitesi tarafindan desteklenmiştir (Proje no: SAG-C-DUP170118-0004).
}

Kaynakça Bilgisi: Yıldırak M, Gözneli R. Diş Beyazlatma İşleminin Lityum Disilikat Seramiğin Bağlanma Dayanımına Etkisi. Atatürk Üniv Diş Hek Fak Derg 2020; 30: 113-121. Citation Information: Yildirak M, Gozneli R. The Effect of Tooth Bleaching on The Shear Bond Strength of a Lithium Disilicate Ceramic. J Dent Fac Atatürk Uni 2020; 30 : 113-121 


\section{GİRİş}

Adeziv diş hekimliğindeki gelişmelere paralel olarak estetik ile ilgili protetik uygulamaların daha konservatif şekilde yapılabilmesi mümkün olmuştur. Bu amaçla kullanılabilen tam seramik restorasyonlar, adeziv rezin bağlanma kapasiteleri ile hem estetik hem de dayanıkııık açısından avantajlar sunmaktadır. Ancak, estetik beklentiler restore edilecek dişin beyazlatılmasını da gerekli kılabilir. Bu amaçla, diş renklerinin çeşitli yöntemlerle non -invaziv olarak beyazlatılması da günümüzde oldukça yaygın bir yöntemdir. ${ }^{1}$

Renklenmenin tipi, bölgesi ve miktarına bağlı olarak beyazlatma amacıyla pek çok farklı ajan kullanılmaktadır. Bu ajanlar; oksidan, eroziv ve abraziv özelliklerde ya da bunların kombinasyonu şeklinde olabilir. Mine ve dentine penetrasyonları yönünden oksidanlar en etkili ajanlar olarak bilinmektedir. Oksidanlar; serbest oksijen radikalleri oluşturup, düşük molekül ağırlığından dolayı minenin prizmatik aralıklarına difüze olurlar ve büyük organik moleküllerden kopardığı küçük molekülleri, köpürme özelliğiyle yüzeye taşırlar. Günümüzde klinikte yapılan beyazlatma işlemlerinde genel olarak kullanılan ajanlar \%3040 konsantrasyonlardaki hidrojen peroksit $\left(\mathrm{H}_{2} \mathrm{O}_{2}\right)$ ve karbamid peroksittir. ${ }^{1,2}$ Beyazlatma işlemini hızlandırmak ya da daha etkin hale getirmek için beyazlatma ajanının ışık, ısı veya lazerle aktivasyonu mümkündür. $\mathrm{Bu}$ sistemler aktive edilmiş beyazlatma prosedürü olarak tanımlanmaktadır. ${ }^{3}$ LED ışığın bu amaçla beyazlatma işlemlerinde kullanılması önerilmektedir. ${ }^{4}$

Beyazlatma işleminin sağladığı güzel estetik sonuçların yanında, istenmeyen bazı olumsuz etkilere de sebep olduğu bilinmektedir. Mine ve dentinin morfolojik özelliklerindeki değişimler, minenin yüzey pürüzlülüğünün artması, minenin reminerilizasyon kapasitesinin değişmesi, yüzey sertliğinin azalması, kırılma dayanımının azalması ve dentin hassasiyeti, gözlenen başlıca olumsuz etkilerdendir. ${ }^{1,5-9}$ Rotstein $^{10}$ ve arkadaşları, \%35'lik hidrojen peroksitin hem minenin hem de dentinin kalsiyum -fosfat oranını belirgin bir şekilde düşürdüğünü göstermişlerdir . Diğer bir istenmeyen etki ise, yüksek konsantrasyonlardaki beyazlatma ajanlarının mineye olan bağlantının azalmasına neden olabilmesidir. ${ }^{11-15}$ Josey ve arkadaşları ${ }^{16}$ ile Murchison ve arkadaşları ${ }^{17}$, beyazlatılmış ve beyazlatılmamış minelerin bağlanma dayanımlarında belirgin bir farklılık olmadığını bildirmişlerdir. Garcia-Godoy ve arkadaşları $^{18}$, \%10 karbamid peroksit ile 24 saat boyunca temas eden mine örneklerinde makaslama bağlanma dayanımının \%40 oranında azaldığını bildirmişlerdir. Bu durum beyazlatılmış minedeki rezin tagların işlem yapılmamış mineye kıyasla daha az sayıda ve daha kısa olmasıyla açıklanmıştır. ${ }^{19}$ Ayrıca doku içerisinde kalmış rezidüel serbest oksijen radikallerinin, rezin materyalinin infiltrasyonunu ve polimerizasyonunu engelleyerek bağlanma dayanımını düşürdüğü bildirilmiştir ve rezidüel hidrojen peroksitin ne kadar sürede elimine olabileceği kesin olarak bilinmemektedir. ${ }^{10,19,20}$

Beyazlatma işlemi sonrası oluşan zayıf bağlanma dayanımının sebep olabileceği durumların önlenebilmesi ve bağlantıyı güçlendirebilmek için pek çok yöntem önerilmektedir. Aseton ya da \%70 alkol gibi kurutucu ajanların kullanımının bağlantıyı olumlu yönde etkilemek için kullanılabilecek yöntemlerden biri olduğu bildirilmiştir. ${ }^{21}$ Beyazlatma sonrası mine yüzeyine antioksidan ajanlar uygulanmasıyla da bağlantıyı arttırmada kullanılabileceği bildirilmiştir. ${ }^{11-13,14,22}$ Beyazlatma tedavisi sonrası restorasyon uygulanmadan beklenmesi de bu yöntemlerden bir diğeri ve en sıklıkla kullanılanıdır. Bu durum kullanılan ajana ve konsantrasyonuna göre değişmekte olup, \%10'luk karbamid peroksit için 24 saat-7 gün, \%35'lik hidrojen peroksit için ise 7 gün-2 hafta sürelerinde bekletilmesi minede bağlantı dayanımının arttırılması için tavsiye edilmektedir.22-24

Protetik tedavi öncesinde yapılan beyazlatma işleminin ve bekleme süresinin restorasyonun bağlanma dayanımını ne oranda etkilediği klinik uygulamalar için oldukça önem taşımaktadır. Bu sebeple çalışmanın amacı, LED ile aktive edilmiş beyazlatma işlemi yapılan mine yüzeylerine 1 . ve 7 . günlerdeki adeziv rezin simantasyonu sonrasındaki lityum disilikat seramik veneerlerin makaslama bağlanma dayanımı değerlerini araştırmak ve kopma paternlerini incelemektir. Çalışmanın sıfır hipotezi, beyazlatmayı takiben hemen simantasyon yapılmış örneklerin bağlanma dayanımlarının, hem kontrol hem de 7.gün simantasyon yapılmış gruba göre düşük olacağı, diğer 2 grup arasında bağlanma kuvveti açısından fark olmayacağıdır.

\section{MATERYAL VE METOD}

\section{Seramik örneklerin hazırlanması:}

Kırk beş adet lityum disilikat seramik disk (IPS e.max Press, Ivoclar Vivadent, Schaan, Liechtenstein) firma talimatlarına göre $1 \mathrm{~mm}$ kalınlığında ve $5 \mathrm{~mm}$ çapta disk şeklinde üretilmiştir. 


\section{Diş örneklerin hazırlanması:}

Kırkbeş adet, periodontal problemler veya travma nedeniyle çekilen homojen boyutlarda üst santral kesici diş kullanıımıştır. Toplanan dişler öncelikle $0,1 \%$ timol solüsyonunda bekletilmiş ve mine-sement yüzeylerinde bulunan diş taşları ve periodontal dokular kavitron cihazı (Lm-Ergo Grip Ultra, Lm Dental, Parainen, Finlandiya) kullanılarak uzaklaştırımıştır. Dişler temizlendikten sonra, doğal nemlerinin korunması amacıyla, distile su içerisinde ve oda ısısında kullanılana kadar bekletilmiştir . Yüzey işlemleri tamamlanan dişlerin mine-sement sınırları kurşun kalem ile işaretlenip. Kondensasyon silikon ölçü maddesi (Zetaplus, Zhermack, Rovigo, İtalya) kullanılarak makaslama bağlanma dayanımının ölçuleceği cihazın tablasıyla uyumlu olan kalıplar hazırlanmışır. Dişler sirkolant mumuyla labial yüzey paralelometrenin işaretleyici ucuyla paralel olacak şekilde konumlandırlıp sabitlenmiş ve otopolimerize akrilik rezin üretici firmanın talimatları doğrultusunda karıştırılarak silikon kalıplara dökülüp ve polimerize edilmiştir. Polimerizasyon sonrası akrilik fazlalıkları tesviye edilmiştir.

\section{Beyazlatma uygulaması:}

Örneklerin 15 tanesi kontrol grubu olarak tasarlanmış ve beyazlatma işlemi uygulanmamıştır. Diğer 30 örneğe preparasyon ve simantasyon işlemleri öncesinde beyazlatma ajanı uygulanmışır. \%32'lik hidrojen peroksit içeren ofis tipi beyazlatma ajanı (fläsh Chairside Light Whitening; WHITEsmile GmbH, Birkenau, Almanya) örneklerin labial yüzeylerine üretici firma önerileri doğrultusunda fırça yardımı ile uygulanmış ve $460 \mathrm{~nm}$ dalga boyundaki LED ışık cihazı (fläsh Whitening Lamp; WHITEsmile GmbH, Birkenau. Almanya) ile aktive edilerek 15 dakika süreyle bekletilmiştir. 15 dakika sonunda beyazlatma ajanı pamuk pelet yardımı ile uzaklaştııı ış̧ıı. Aynı uygulama $2 \mathrm{kez}$ daha tekrarlanmış, 15'er dakikalık 3 uygulama yapılmıştır. Böylece beyazlatııı ajan toplam 45 dakika süre ile uygulanmıştır. Beyazlatma işlemi sonrası örnekler $37^{\circ} \mathrm{C}^{\prime}$ lik distile su içerisinde bekletilmiştir.

Dis preparasyonu, simantasyon ve makaslama bağlanma dayanım testi;

Kırk beş adet örnek 0,3 mm derinlikte rehberli frezler (Ökodent Gruppe, Tautenhain, Thüringen, Almanya) kullanılarak mine seviyesinde oluklar açıldıktan sonra, chamfer elmas frez (Hager\&Meisinger, Nouss, Almanya) ile oluklar birleştirilerek labial yüze paralel olan düz bir yüzey elde edilmiştir. Bu işlemler paralelometreye monte edilmiş bir yüksek devirli el aleti kullanılarak yapılmıştır. Yüzey özelliklerinin standardizasyonu için 600 grit silikon karbit zımpara ile su soğutması altında yüzeylerin standardizasyonu sağlanmıştır.

Diş ve seramik örnekler eşit sayıda 3 gruba ayrılmıştır (Tablo 1). Seramik örnekler; 1.grup beyazlatma yapılmadan (Grup K), 2.grup beyazlatma yapılmasını takiben hemen (Grup B0), 3.grup beyazlatma yapılmasını takiben 7 gün sonra (Grup B7) diş preparasyonları tamamlanıp, dual-cure bir sistem olan Variolink $\mathrm{N}$ adeziv rezin siman (Renk: $\mathrm{A} 1 \mathrm{baz}$, transparan katalizör) (Ivoclar Vivadent, Schaan, Liechtenstein) kullanılarak, diş örneklerin labial yüzeyi ortasına simante edilmiştir.

Tablo 1. Çalışma grupları

\begin{tabular}{|l|c|c|}
\hline Grup & Uygulanan işlem & $\mathbf{N}=\mathbf{4 5}$ \\
\hline K & Beyazlatma uygulanmadan simantasyon & $\mathrm{n}=15$ \\
\hline B0 & $\begin{array}{c}\text { Beyazlatmadan hemen sonra } \\
\text { simantasyon }\end{array}$ & $\mathrm{n}=15$ \\
\hline B7 & Beyazlatmadan 7 gün sonra simantasyon & $\mathrm{n}=15$ \\
\hline
\end{tabular}

Simante edilen tüm gruplardaki örnekler makaslama bağlanma dayanımları öncesinde 24 saat süreyle $37{ }^{\circ} \mathrm{C}^{\prime}$ lik distile su içerisinde bekletilmiştir. Makaslama bağlanma dayanımı testi Universal test cihazında (AG5 kNG, Shimadzu, Tokio, Japonya), 0,5 mm/dak hızda kopma anına kadar kuvvet uygulanmıştır.

\section{Kopma paternlerinin değerlendirmesi:}

Makaslama bağlanma dayanım testi sonrası kopan tüm seramik ve diş örneklerinin simantasyon yüzeyleri ışık mikroskobu ile (Zeiss Axio Zoom V.16; Carl Zeiss Microscopy GmbH, Jena, Almanya) x20 büyütmede incelenerek kopma paternleri belirlenmiştir.

Kopma paternleri Albalkhi ve arkadaşlarının araştırmalarında tanımlanan kriterlere göre üç tipte sınıflandırılmıştır (Şekil 1). ${ }^{25}$

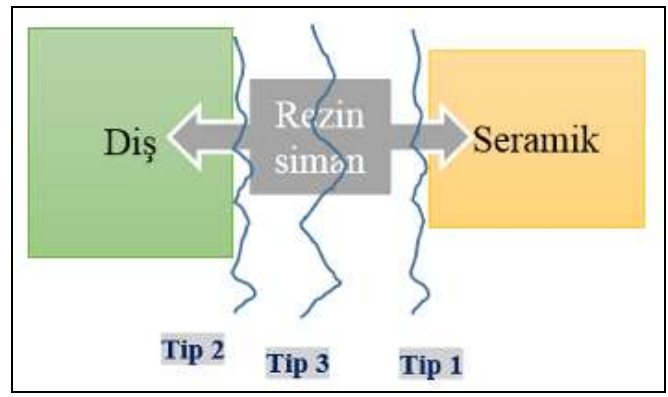

Şekil 1. Şematik olarak kopma paternleri. 
Tip 1 adeziv kopma: Kopmanın "rezin siman/veneer" arasından oluşmasıdır. Rezin simanın çoğu diş yüzeyinde kalır.

Tip 2 adeziv kopma: Kopmanın "rezin siman/diş yüzeyi" arasından oluşmasıdır. Rezin simanın çoğu veneer seramik yüzeyinde kalır.

Tip 3 koheziv kopma: Kopmanın rezin simanın içinde oluşmasıdır. Rezin siman hem diş hem de seramik yüzeyinde eşite yakın miktarda kalır.

Ístatistiksel analiz ve verilerin yorumlanması

Makaslama bağlanma dayanımı testi ölçümleri sonucunda elde edilen verilerin istatistiksel analizleri için SPSS (Statistical Package for Social Sciences for Windows 23.0) programı (SPSS Inc, Chicago, Illinoise, $A B D$ ) kullanılmıştır. Normal dağılım gösteren verilerin karşılaştırılmasında tek yönlü varyans analizi (one-way ANOVA) kullanılırken, gruplar arasındaki farklılığın nereden kaynaklandığını bulmak için Bonferroni düzeltmeli ortalama karşılaştırması yapılmıştır. Kopma paternlerine ait verilerin sunumu frekans (yüzde) olarak yapılmıştır.

Tablo 2. Beyazlatma sonrası makaslama bağlanma dayanımının günlere göre değişiminin karşılaştırıması

\begin{tabular}{|l|c|c|c|}
\hline Grup & Ortalama \pm S.Sapma (MPa) & $\begin{array}{c}\text { Test } \\
\text { İstatistiği }\end{array}$ & p \\
\hline K & $30,04 \pm 1,19 \mathrm{a}$ & $\mathrm{F}=156,978$ & $<0,001$ \\
\cline { 1 - 2 } B0 & $20,34 \pm 1,81 \mathrm{~b}$ & & \\
\cline { 1 - 2 } B7 & $27,02 \pm 1,24 \mathrm{c}$ & & \\
\hline
\end{tabular}

F:Tek yönlü varyans analizi test istatistiği, a-c: Aynı harfe sahip gruplar arasında fark yoktur.

Tablo 3. Gruplara göre kopma paternlerinin incelenmesi

\begin{tabular}{|l|c|c|c|}
\hline Grup & Tip 1 (\%) & Tip 2 (\%) & Tip 3 (\%) \\
\hline K & 66,7 & -- & 33,3 \\
\hline B0 & -- & 80 & 20 \\
\hline B7 & 46,7 & 20 & 33,3 \\
\hline
\end{tabular}

\section{BULGULAR}

Kontrol grubunun ortalama makaslama bağlanma dayanımı değerleri 30,04 MPa iken beyazlatma sonrası 1 . günde ortalama makaslama bağlanma dayanımı değerleri 20,34 MPa'a düşmüş ve 7. günde de 27,02 MPa'a çıkmıştır (Şekil 2). Beyazlatmadan hemen sonra restore edilen dişlerde bağlanma kuvveti anlamlı miktarda azalmıştır $(p<0,001)$. Yedi gün bekletildikten sonra makaslama bağlanma dayanımı, beyazlatmadan hemen sonra ölçülen değerlere kıyasla artış sağlamıştır, ancak, bu artış kontrol grubunun makaslama bağlanma dayanımı kadar yüksek değildir. Beyazlatma sonrası ortalama makaslama bağlanma dayanımı değerleri günlere göre farklılık göstermektedir ( $p<0,001)$. Üç gruptan elde edilen ortalama makaslama bağlanma dayanımı değerleri arasında istatistiksel olarak anlamlı fark vardır (Tablo2).

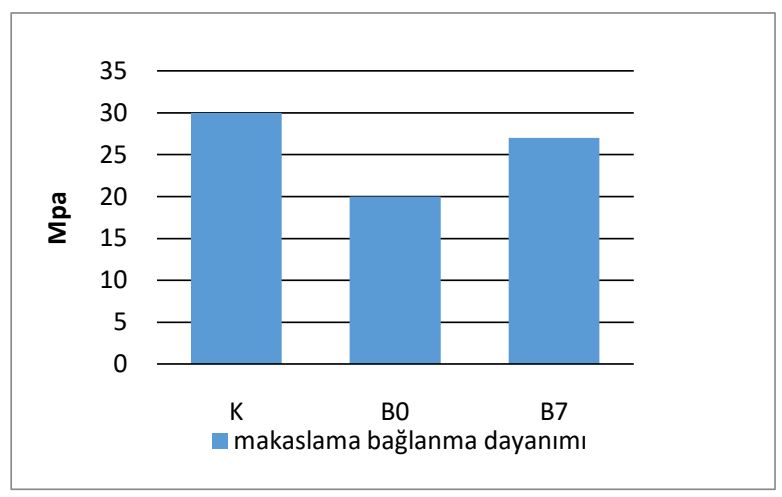

Şekil 2. Grupların makaslama bağlanma dayanımı bulguları

K grubundaki örneklerin \% 66,7'sinde "rezin siman/seramik" arasından tip 1 adeziv kopma (Şekil 3) ve $\% 33,3$ 'ünde hem seramik hem de mine yüzeyinde neredeyse eşit miktarda rezin siman bulunan tip 3 koheziv kopma (Şekil 4) görülürken, tip 2 kopma paterni görülmemiştir. B0 grubundaki örneklerde en sık görülen kopma, \% 80 "rezin siman/diş" arasında oluşan tip 2 adeziv kopma paterni (Şekil 5) ve \% 20 oranında tip 3 koheziv kopma paterni (Şekil 4) şeklindedir. Tip 1 kopma paterni görülmemiştir. B7 grubunda \% 46,7 oranında tip 1, \% 20 oranında tip 2 ve $\% 33,3$ oranında tip 3 olmak üzere tüm kopma paternleri görülmüştür (Tablo3) (Şekil 6).

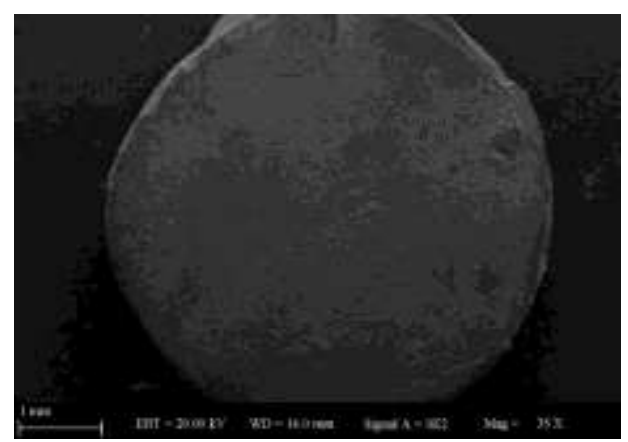

Şekil 3. Tip 1 kopma paterni görülen seramik yüzeyi SEM görüntüsü (x35) 


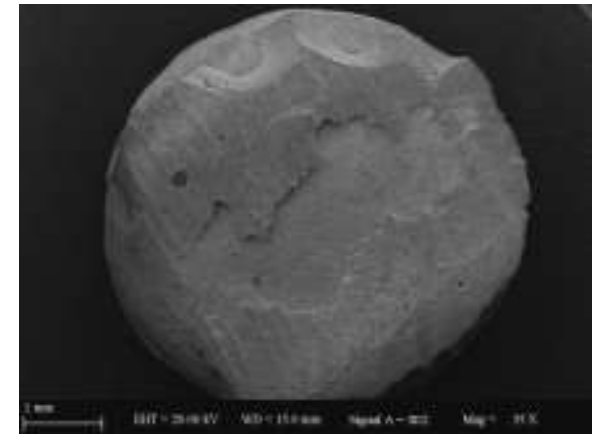

Şekil 4. Tip 3 kopma paterni görülen seramik yüzeyi SEM görüntüsü (x35)

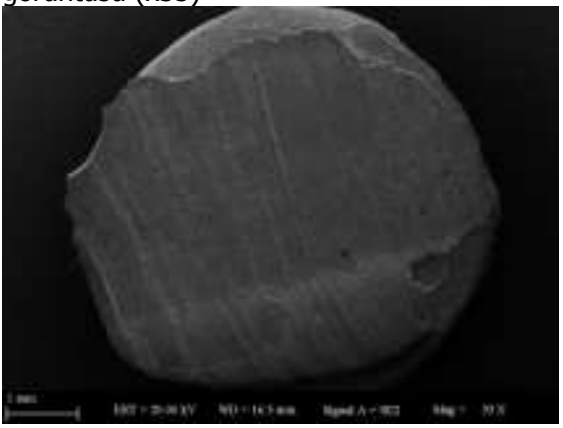

Şekil 5. Tip 2 kopma paterni görülen seramik yüzeyi SEM görüntüsü (x33)

\begin{tabular}{|c|c|c|c|}
\hline $100 \%$ & \multicolumn{2}{|c|}{ Kopma Paterni } & \\
\hline $0 \%$ & K & BO & B7 \\
\hline$\square \operatorname{Tip} 1$ & 66,7 & 0 & 46,7 \\
\hline - Tip 2 & 0 & 80 & 20 \\
\hline$\square$ Tip 3 & 33,3 & 20 & 33,3 \\
\hline
\end{tabular}

Şekil 6. Gruplara göre kopma paternlerinin incelenmesi

\section{TARTIŞMA}

Günümüzde estetiğin her geçen gün daha da önem kazanması diş beyazlatma tedavilerine olan ilgiyi oldukça arttırmıştır. Fakat beyazlatma tedavileri estetik olarak istenilen sonuçları meydana getirmesine rağmen, tedavisi süresince ve sonrasında diş, se rt dokularında değişimler ve restoratif materyal ile diş dokusu arasındaki bağlanma kuvvetlerinde azalma gibi negatif etkilerinin olması, beyazlatılmış dişlere restorasyonların uygulanması için en ideal zamanın belirlenmesi açısından önem kazanmıştır ${ }^{25}$ Bu çalışmada, çekilmiş üst santral dişlere, LED ışık cihazı ile aktive edilerek uygulanan ofis tipi beyazlatma işleminin farklı bekleme süreleri sonrasındaki, mine yüzeyinde prepare edilip simante edilen lityum disilikat seramik veneerlerin makaslama bağlanma dayanımları üzerindeki etkileri araştırılmıştır. Çalışma sonucunda elde edilen veriler doğrultusunda, beyazlatmayı takiben hemen simantasyon yapılmış örneklerin bağlanma dayanımlarının, hem kontrol hem de 7.gün simantasyon yapılmış gruba göre düşük olacağı hipotezi kabul edilirken, diğer 2 grup arasında bağlanma kuvveti açısından fark olmama hipotezi reddedilmiştir.

$\mathrm{Bu}$ çalışmaya göre $\mathrm{K}$ grubunun ortalama makaslama bağlanma dayanımı değerleri 30,04 MPa iken B0 grubunun ortalama makaslama bağlanma dayanımı değerleri 20,34 MPa'a düşmüş ve B7 grubunda 27,02 MPa'a çıkmıştır. B0 grubu için bağlanma dayanımı istatistiksel olarak anlamlı derecede azalmıştır $(p<0,001)$. Beyazlatma sonrası bekleme süresinin ortalama makaslama bağlanma dayanımı değerlerini etkilediği görülmüştür $(p<0,001)$. Bu bulgular makaslama bağlanma dayanımı açısından, beyazlatmanın braket ve/veya kompozit rezin materyallerinin kullanılarak araştırıldığı bir çok çalışma ile benzerlik gösterse de kopma paterni açısından farklı sonuçlar elde edilmiştir. ${ }^{11,13,14,19,22,24,26-}$ 28 Diğer taraftan, yapılan bazı çalışmalarda ise, bağlanma dayanımı değerlerinde anlamlı farklılıklar bulunmadığı bildirilmiştir. ${ }^{17,29}$

Beyazlatma işlemini takiben hidrojen peroksit ve karbamid peroksit uygulanmasına bağlı olarak, diş yüzeyinde veya iç kısımlarında kalan artık oksijenin "rezin siman-diş" bağlantısını inhibe ederek veya rezinin polimerizasyonunu engelleyerek bağlanma dayanımı değerlerini düşürdüğü bildirilmiştir . 16,19,30-32 Ayrıca mine yüzeyinin pürüzlülüğünün ve porözitesinin artması, daha kısa ve az sayıda rezin tag oluşması, mikro sertlikteki düşüş, mine ve dentindeki mekanik özelliklerdeki ve kalsiyum, fosfor, sülfür ve potasyum miktarındaki değiş̧iklikler de bağlanma dayanımını düşüren sebepler olarak bildirilmiştir. ${ }^{33,34}$ Rostein ve arkadaşları $^{10}$, beyazlatma ajanlarının diş dokusunda kalsiyum, fosfor, kükürt ve potasyum seviyesinde değişikliklere neden olduğunu ve Ca ile $\mathrm{P}$ oranındaki değişikliklerle hidroksiapatit yapının organik bileşenlerinde değişime sebep olduğu gösterilmiştir. \%35'lik hidrojen peroksit uygulanmış, mine yüzeyinde SEM bulgularına göre bağlantının olmadığı boşluklar saptanırken, oluşan rezin taglari kırık , zor tanımlanan ve derinliği çok az olduğu ifade edilmiştir. ${ }^{19}$ Perdigao ve arkadaşları $^{20}$ tarafından yapılan bir çalışmada, \%10'luk karbamid peroksit uygulanmış, mine dokusunda , oksijen konsantrasyonu değişmez iken, minenin en üst tabakasında protein ve mineral içeriğinin değiştiği ya 
da morfolojik değişiklikler sonucu bağlantı dayanımının azalabileceği bildirilmiştir.

Beyazlatma sonrası bağlanma dayanımındaki azalmanın miktarını etkileyen faktörlerden birisi de kullanılan ajanın çeşidi ve konsantrasyonudur. Düşük konsantrasyonlardaki ajanlar ile yapılan beyazlatma işlemi sonrası mine yüzeyinde bağlanma dayanımının etkilenmediğini bildiren çalışmalar mevcuttur. ${ }^{35,36}$ Barbosa ve arkadaşları $^{35}$ yaptıkları çalışmada $\% 16$ karbamid peroksit içeren ev tipi beyazlatma ajanının kompozit rezinin mine ve dentine makaslama bağlanma dayanımı üzerindeki etkisi araştırmışlartır. Beyazlatma tedavisinin bitiminden hemen sonra, 7 gün sonra ve 14 gün sonra makaslama bağlanma dayanımı değerleri ölçülmüştür. Makaslama bağlanma dayanımı değerleri arasında anlamlı farklılıkların olmadığı bildirilmiş ve restoratif prosedürlerin beyazlatmanın bitiminden hemen sonra uygulanabileceği sonucuna varılmıştır. Cura ve arkadaşlarının ${ }^{36}$ yaptıkları çalışmada \%10 karbamid peroksit ve \%10 hidrojen peroksit ajanları kullanılarak yapılan beyazlatma işlemi sonunda mine yüzeyindeki bağlanmanın etkilenmediği bildirilmiştir. Bu çalışmaların aksine, \% 10'luk karbamid peroksit gibi düşük konsantrasyonlu beyazlatma ajanları kullanıldığında bile mine yüzeyinde bağlanma dayanımının azaldığını bildiren çalışmalar da vardır. ${ }^{37,38}$ Peroksit içeren beyazlatıcı ajanların, düşük moleküler ağırlığa sahip olduklarından hızla nüfus etmelerinden dolayı sadece yüzeyde değil, minenin iç yapısında da organik fazı etkiledikleri rapor edilmiştir. ${ }^{39}$ Cura ve arkadaşları $^{36} \% 1^{\prime} 0^{\prime} l u k$ karbamid peroksit gibi düşük konsantrasyonlardaki ajanların kullanımında mine yüzeyinin $50 \mu \mathrm{m}$ 'lik bir derinliğe kadar demineralizasyonunun gerçekleştiğini bildirmiştir.

Beyazlatma işlemi yapılmış dişlere uygulanacak restorasyonların klinik başarısının sağlanabilmesi için azalan bağlantının iyileştirilebilmesi için birkaç yöntem önerilmiştir. Bunlardan bazıları etkili ve konservatif bir uygulama olmayan yüzeysel minenin tamamen kaldırıması, alkol bazlılar yerine etanol ya da aseton bazlı bonding ajan uygulanması, diş yüzeyine aseton ya da \%70 alkol gibi kurutucu ajanların uygulanması ve antioksidan ajanların kullanılmasıdır. ${ }^{11-15,21,22,25,40}$ Ayrıca en kolay uygulanan ve en çok tavsiye edilen diğer bir yöntem, restorasyon yapılana kadar 24 saatle 4 hafta arasında değişen sürelerde beklenmesidir. Kullanılan beyazlatma ajanına ve konsantrasyonuna göre beklenmesi gereken süre ile ilgili çeşitli sonuçlar bildirilmiştir. ${ }^{23,41} \% 10^{\prime}$ luk karbamid peroksit için 24 saat-7 gün, \% 35'lik hidrojen peroksit için ise 7 gün sürelerince yapay tükürükte bekleme periyodları mine bağlantı dayanımının yeniden sağlanması için tavsiye edilmektedir. ${ }^{22-24}$ Bazı çalışmalarda da beyazlatma ile restorasyon arasında geçen zamanın 2 hafta olması tavsiye edilmektedir. ${ }^{42,43}$ Bu sürenin 3 hafta olabileceğine dair çalışmalar da bulunmaktadır. ${ }^{38}$ Yedi günlük bekleme periyodunun bağlantı üzerinde etkili olmadığını, ancak 14 günlük beklemenin etkili olduğunu gösteren bir çalışma da mevcuttur. ${ }^{27}$ Araştırmacılar, aktive edilmiş, hidrojen peroksit uygula masını takiben restorasyon yapılması için aktive edilmemiş, beyaz latma işlemlerine kıyasla daha uzun bir bekleme süresi gerekebileceğini bildirmişlerdir . ${ }^{44}$ Liu ve arkadaşları ${ }^{45}$, \%35 hidrojen peroksit içeren beyazlatma ajanı ile beyazlatma sonrası minede bağlanma kuvvetiyle zaman arasındaki ilişkiyi araştırdıkları çalışmalarında rezinin mineye bağlanma kuvvetini 2 hafta boyunca düşük bulmuşlar ve porselen veneer bağlanma işleminin yapılması için beyazlatma sonrası 2 hafta beklenmesini tavsiye etmişlerdir. Araştırmacılar, beyazlatma işlemi ile adeziv rezin arasında en az 7 gün bekleme süresi olması gerektiğini önermişlerdir. ${ }^{42,47}$ Bekleme süresinin 1 saat ile 4 hafta arasında değiştiğini bildiren çalışmalar olmasına rağmen, ${ }^{19,39}$ en çok tavsiye edilen 1 hafta süreyle beklenmesidir. ${ }^{42,43} \mathrm{Bu}$ çalışmada bekleme süreleri olarak 1 hafta bekleme süresinin \% 32 hidrojen peroksit içeren beyazlatma ajanının LED ışık ile aktive edilerek ofis tipi beyazlatma uygulamalarından sonra bağlanma değerlerinde bir farklılık yaratıp yaratmayacağını araştırılmıştır.

İn-vivo çalışmalarda ağız ortamında bulunan tükürüğün ve in-vitro çalışmalarda ağız ortamını daha iyi taklit edebilmek için kullanılan inorganik içerikli yapay tükürüğün kalsiyum ve fosfat iyonları içermesi, uygulamalar arasında bu solüsyonlarda bekleyen dişlerin reminerilizasyonuna katkıda bulunmakta ve daha yüksek değerler elde edilebilmektedir. ${ }^{48}$ Lago ve Garone-Netto ${ }^{24}$, \%35' lik hidrojen peroksit uygulamasını takiben 7 gün boyunca yapay tükürükte bekletmenin bağlantı başarısı için yeterli olduğu

sonucuna ulaşmış ve 14 gün bekletme ile 7 gün bekletme arasında bir fark olmadığını belirtmişlerdir . Uysal ve arkadaşları ${ }^{49}$ ise, beyazlatılmış dişleri yapay tükürükte bekletmenin restorasyonların makaslama bağlanma dayanımı üzerinde önemli bir etki yaratmadığını, bağlanma zamanının 2 veya 3 hafta ertelenmesinin daha etkili olduğunu belirtmişlerdir . Whang ve Shin ${ }^{26}$ ise yaptıkları çalışmada distile su kullanmış olup, 4 hafta distile suda bekletmenin bağlantıyı beyazlatma öncesi seviyeye yükselttiğini 
göstermiştir. Bu çalışmada örnekler 1 hafta sürede birçok çalışmada tercih edildiği gibi örneklerin diğer faktörlerden etkilenmemesi ve bağlanma dayanımı değerlerini net şekilde yansıtması için $37{ }^{\circ} \mathrm{C}^{\prime}$ deki distile suda bekletilmiştir.

Tam seramik restorasyonların adeziv rezin ile simantasyonunda, "diş-rezin siman" ve 'rezin simanseramik" arasında olmak üzere 2 adet bağlantı mekanizması bulunur. ${ }^{50}$ Bağlanma dayanımı testleri ile bu yapının bir bütün olarak kuvvetlere dayanımı ölçülürken kopmanın hangi alanda gerçekleştiği yani bağlantının en zayıf noktası açıklanamamaktadır. Kopmanın hangi alanda olduğunu tespit edebilmemizi sağlayabilen ve diş ile seramik restorasyonda hasar meydana gelme olasılıklarını değerlendiren en önemli indeks kopma paternlerinin tespitidir. ${ }^{51}$ Kontrol grubunda 'rezin siman-seramik" arasında oluşan adeziv kopma olan tip 1 ve rezin simanın kendi içerisinde oluşan koheziv bir kopma olan tip 3 kopma paterni görülmüştür. Bu durum mine - rezin siman arasındaki bağlantının rezin siman - seramik bağlantısından daha kuvvetli olmasıyla açıklanır. B0 grubunda tip 1 bağlantı görülmeyip \%80 "diş-rezin siman" siman arasında oluşan adeziv kopma paterni görülmüştür. Beyazlatma ajanının uygulanmasından hemen sonra mine yapısındaki değişiklikler ve artık serbest oksijen radikallerinin mine yapısında kalması, mine ve rezin siman bağlantısını düşürdüğünden bu iki yapı arasında kopma meydana geldiği görülmüştür. Buna bağlı olarak, beyazlatmayı takiben hemen simante edilen tam seramik restorasyonlarda "debonding" komplikasyonunun sıklığının artabileceği söylenebilir. B7 grubunda bağlanma dayanımı $\mathrm{K}$ grubuna yaklaşmasına rağmen, $\mathrm{K}$ grubundan farklı olarak tip 2 (adeziv) kopmalar da meydana geldiği görülmektedir. Bu sonuç, beyazlatma uygulandıktan sonra bekleme işleminin, bağlanma dayanımını değerlerinde artış sağlasa da elde edilen diş/rezin siman bağlantısına hala etkisinin nispeten devam ettiğini göstermektedir.

Yapılan bu çalışmada, termal siklusun oluşturabileceği olası etkiler değerlendirilmemiştir. Gelecekte yapılacak çalışmalarda bu etkiler de göz önüne alınarak LED ışık ile aktive edilmiş hidrojen peroksit uygulanan diş yüzeylerindeki yapısal değişiklikler ve bağlantı etkinlikleri değerlendirilebilir.

\section{SONUÇLAR}

Bu çalışmanın sınırlamaları dahilinde elde edilen verilerden yola çıkarak şu sonuçlar elde edilmiştir;
1. LED ışık ile aktive edilen $\% 32$ 'lik hidrojen peroksit beyazlatma ajanının uygulanmasından hemen sonra lityum disilikat veneerlerin simante edilmesi bağlanma dayanımını olumsuz etkiler ve bağlanma dayanımı azalır.

2. Beyazlatıcı ajan uygulamasını takiben 1 hafta beklemenin bağlantı başarısızlığını nispeten iyileştireceği, ancak, beyazlatma öncesi seviyeye ulaşmak için yetersiz kalabileceği görülmüştür.

3. Kontrol grubunda ve beyazlatma gruplarında kopma paterni farklılık göstermektedir. Beyazlatma işlemi sonrası diş yüzeyine olan bağlantının azalmasına bağlı olarak "rezin siman/diş" arasında oluşan Tip 2 kopma paterni görülme sıklığı artar.

NOT: Calışmada herhangi bir yazar, kurum ya da kuruluş ile çıkar çatışması içerisinde bulunmamaktadır. Makale daha önce hiçbir yerde yayınlanmamış ve yayınlanmak üzere işlem görmemektedir

\section{KAYNAKLAR}

1. O'Brien WJ. Dental materials and their selection. 4th ed. Chicago, Quintessence Pub. Co., 2008. p. 165-166.

2. Karadaş M, Seven N. Vital dişlerde beyazlatma. Atatürk Üniv Diş Hek Fak Derg 2014; 3:126-35.

3. Buchalla W, Attin T. External bleaching therapy with activation by heat, light or laser--a systematic review. Dent Mater 2007; 23: 586-96.

4. Lin $\mathrm{CH}$, Chou TM, Chen $\mathrm{JH}$, Chen JH, Chuang FH, Lee $\mathrm{HE}$, Coluzzi DJ. Evaluation of the effect of laser tooth whitening. Int J Prosthodont 2008; 21:415-8.

5. Pinto CF, Oliveira Rd, Cavalli V, Giannini M. Peroxide bleaching agent effects on enamel surface microhardness, roughness and morphology. Braz Oral Res 2014; 18:306-11.

6. Attin T, Schmidlin PR, Wegehaupt F, Wiegand A. Influence of study design on the impact of bleaching agents on dental enamel microhardness: a review. Dent Mater 2009; 25:143-57.

7. Carvalho AO, Ayres APA, de Almeida LCAG, Briso ALF, Rueggeberg FA, Giannini M. Effect of peroxide bleaching on the biaxial flexural strength and modulus of bovine dentin. Eur J Dent 2015; 9:24650.

8. Bonafe $\mathrm{E}$, Bacovis $\mathrm{CL}$, Iensen $\mathrm{S}$, Loguercio $A D$, Reis $A$, Kossatz $S$. Tooth sensitivity and efficacy of inoffice bleaching in restored teeth. J Dent 2013;41: 363-9. 
9. Potocnik I, Kosec L, Gaspersic D. Effect of $10 \%$ carbamide peroxide bleaching gel on enamel microhardness, microstructure, and mineral content. J Endod 2000; 26:203-6.

10. Rotstein I, Dankner E, Goldman A, Heling I, Stabholz A, Zalkind M. Histochemical analysis of dental hard tissues following bleaching. J Endod 1996; 22: 23-5.

11. Abraham S, Ghonmode WN, Saujanya KP, Jaju N, Tambe VH, Yawalikar PP. Effect of grape seed extracts on bond strength of bleached enamel using fifth and seventh generation bonding agents. J Int Oral Health 2013; 5:101-7.

12. Khamverdi Z, Rezaei-Soufi L, Kasraei S, Ronasi N, Rostami S. Effect of Epigallocatechin Gallate on shear bond strength of composite resin to bleached enamel: an in vitro study. Restor Dent Endod 2013; 38:241-7.

13. Güler $E$, Gönülol N, Özyilmaz ÖY, Yücel AÇ. Effect of sodium ascorbate on the bond strength of silorane and methacrylate composites after vital bleaching. Braz Oral Res 2013; 27:299-304.

14. Arumugam MT, Nesamani R, Kittappa K, Sanjeev $\mathrm{K}$, Sekar M. Effect of various antioxidants on the shear bond strength of composite resin to bleached enamel: An in vitro study. J Conserv Dent 2014; 17: 22-6.

15. Benni DB, Naik SN, Subbareddy VV. An in vitro study to evaluate the effect of two ethanol-based and two acetone-based dental bonding agents on the bond strength of composite to enamel treated with $10 \%$ carbamide peroxide. J Indian Soc Pedod Prev Dent 2014; 32:207-11.

16. Josey AL, Meyers IA, Romaniuk K, Symons AL. The effect of a vital bleaching technique on enamel surface morhology and the bonding of composite resin to enamel. J Oral Rehabil 1996; 23:244-50.

17. Murchison DF, Charlton DG, Moore BK. Carbamide peroxide bleaching: effects on enamel surface hardness and bonding. Oper Dent 1992; 17:181-5.

18. Garcia-Godoy F, Dodge WW, Donohue M, O'Quinn JA. Composite resin bond strength after enamel bleaching. Oper Dent 1993;18:144-7.

19. Titley KC, Torneck CD, Smith DC, Chernecky R, Adibfar A. Scanning electron microscopy observations on the penetration and structure of resin tags in bleached and unbleached bovine enamel. J Endod 1991; 17:72-5.
20. Perdigao J, Francci C, Swift EJ, Ambrose WW, Lopes M. Ultra-morphological study of the interaction of dental adhesives with carbamide peroxide-bleached enamel. Am J Dent 1998; 11:291-301.

21. Niat AB, Yazdi FM, Koohestanian N. Effects of drying agents on bond strength of etch-and-rinse adhesive systems to enamel immediately after bleaching. J Adhes Dent 2012; 14:511-6.

22. Miranda TA, Moura SK, Amorim VH, Terada RS, Pascotto RC. Influence of exposure time to saliva and antioxidant treatment on bond strength to enamel after tooth bleaching: an in situ study. J Appl Oral Sci 2013; 21:567-74.

23. Unlu N, Cobankara FK, Ozer F. Effect of elapsed time following bleaching on the shear bond strength of composite resin to enamel. J Biomed Mater Res B Appl Biomater 2008; 84:363-8.

24. Lago AD, Garone-Netto N. Microtensile bond strength of enamel after bleaching. Indian J Dent Res 2013; 24:104-9.

25. Khoroushi M, Aghelinejad S. Effect of postbleaching application of an antioxidant on enamel bond strength of three different adhesives. Med Oral Patol Oral Cir Bucal 2011; 16:e990-6.

26. Whang $\mathrm{HJ}$, Shin $\mathrm{DH}$. Effects of applying antioxidants on bond strength of bleached bovine dentin. Restor Dent Endod 2015; 40:37-43.

27. Kılınç Hİ, Aslan T, Kılıç K, Er Ö, Kurt G. Effect of delayed bonding and antioxidant application on the bond strenght to enamel after internal bleaching. J Prosthodont 2016; 25:386-91.

28. Subramonian R, Mathai V, Christaine Angelo JB, Ravi J. Effect of three different antioxidants on the shear bond strength of composite resin to bleached enamel: An in vitro study. J Conserv Dent 2015; 18: 144-8.

29. Cullen DR, Nelson JA, Sandrik JL. Peroxide bleaches: effect on tensile strength of composite resins. J Prosthet Dent 1993; 69:247-9.

30. Feiz A, Khoroushi M, Gheisarifar M. Bond strength of composite resin to bleached dentin: effect of using antioxidant versus buffering agent. J Dent (Tehran) 2011;8:60-6.

31. Nour El-din AK, Miller BH, Griggs JA, Wakefield C. Immediate bonding to bleached enamel. Oper Dent 2006;31:106-14. 
32. Oz FD, Kutuk ZB. Effect of various bleaching treatments on shear bond strength of different universal adhesives and application modes. Restor Dent Endod $2018 ; 43:$ e20.

33. Cadenaro M, Breschi L, Antoniolli F, Mazzoni A, Di Lenarda $R$. Influence of whitening on the degree of conversion of dental adhesives on dentin. Eur J Oral Sci 2006; 114:257-62.

34. Loretto SC, Braz R, Lyra AM, Lopes LM. Influence of photopolymerization light source on enamel shear bond strength after bleaching. Braz Dent J 2004; 15:133-7.

35. Barbosa CM , Sasaki RT , Flório FM, Basting RT. Influence of in situ post-bleaching times on resin composite shear bond strength to enamel and dentin. Am J Dent 2009; 22:387-92.

36. Cura M, Fuentes MV, Ceballos L. Effect of lowconcentration bleaching products on enamel bond strength at different elapsed times after bleaching treatment. Dent Mater J 2015; 34:203-10.

37. Barcellos DC, Benetti P, Fernandes VV Jr, Valera MC. Effect of carbamide peroxide bleaching gel concentration on the bond strength of dental substrates and resin composite. Oper Dent 2010; 35:463-9.

38. Cavalli V, Reis AF, Giannini M, Ambrosano GM. The effect of elapsed time following bleaching on enamel bond strength of resin composite. Oper Dent 2001; 26:597-602.

39. Lewinstein I, Fuhrer N, Churaru N, Cardash $\mathrm{H}$. Effect of different peroxide bleaching regimens and subsequent fluoridation on the hardness of human enamel and dentin. J Prosthet Dent 2004; 92:33742.

40. Ozelin AA, Guiraldo RD, Carvalho RV, Lopes MB, Berger SB. Effects of green tea application time on bond strength after enamel bleaching. Braz Dent J 2014; 25:399-403.

41. Spyrides GM , Perdigão J , Pagani C , Araújo MA , Spyrides SM. Effect of whitening agents on dentin bonding. J Esthet Dent 2000; 12:264-70.

42. Tabatabaei MH, Arami S, Nojouman A, Mirzaei M. Antioxidant effect on the shear bond strength of composite to bleached bovine dentin. Braz J Oral Sci 2011; 10:33-6.

43. Bishara SE, Oonsombat C, Soliman MM, Ajlouni R, Laffoon JF. The effect of tooth bleaching on the shear bond strength of orthodontic brackets. Am J Orthod Dentofacial Orthop 2005; 128:755-60.
44. Can-Karabulut DC, Karabulut B. Shear bond strength to enamel after power bleaching activated by different sources. Eur J Esthet Dent 2010; 5:382-96.

45. Liu F, Xu MM, Zhang F, Yang YD. Relationship between resin bonding strength and time on deep enamel after bleaching treatment. Zhonghua Kou Qiang Yi Xue Za Zhi 2008; 43:360-1.

46. Da Silva Machado J, Cândido MS, Sundfeld RH, De Alexandre RS, Cardoso JD, Sundefeld ML. The influence of time interval between bleaching and enamel bonding. J Esthet Restor Dent 2007; 19:111-8.

47. Dishman MV, Covey DA Baughan LW. The effects of peroxide bleaching on composite to enamel bond strength. Dent Mater 1994; 10:33-6.

48. Musanje L, Darvell BW. Aspects of water sorption from the air, water and artificial saliva in resin composite restorative materials. Dent Mater 2003; 19:414-22.

49. Uysal T, Basciftci FA, Usümez S , Sari Z, Buyukerkmen A. Can previously bleached teeth be bonded safely? Am J Orthod Dentofacial Orthop 2003; 123:628-32.

50. Peumans M, Van Meerbeek B, Lambrechts $P$, Vanherle G. Porcelain veneers: a review of the literature. J Dent 2000; 28:163-77.

51. Leonetti Edos S, Rodrigues JA, Reis AF, Navarro RS, Aranha AC, Cassoni A. Effects of Er:YAG laser irradiation on the microtensile bond strength to bleached enamel. Photomed Laser Surg 2011; 29:551-8.

\author{
Yazışma Adresi \\ Dt. Merve Yildirak \\ Marmara Üniversitesi \\ Diş Hekimliği Fakültesi \\ 34854 Başıbüyük, Maltepe \\ İstanbul, Türkiye \\ Tel: 02164121621 \\ Fax: 02164210291 \\ E-mail: merve.karagoz@marmara.edu.tr
}

